\title{
Inflammation produces catecholamine resistance in obesity via activation of PDE3B by the protein kinases IKK $\varepsilon$ and TBK1
}

\author{
Jonathan Mowers ${ }^{1,2,3 \dagger}$, Maeran Uhm ${ }^{1,2,3 \dagger}$, Shannon M Reilly ${ }^{1}$, Joshua Simon ${ }^{1}$, Dara \\ Leto $^{1 \neq a}$, Shian-Huey Chiang ${ }^{1 \neq b}$, Louise Chang ${ }^{1}$, Alan R Saltiel ${ }^{1,2,3 *}$
}

${ }^{1}$ Life Sciences Institute, University of Michigan, Ann Arbor, United States; ${ }^{2}$ Department of Internal Medicine, University of Michigan, Ann Arbor, United States; ${ }^{3}$ Department of Molecular and Integrative Physiology, University of Michigan, Ann Arbor, United States

*For correspondence: saltiel@ umich.edu

These authors contributed equally to this work

'Present address: aDepartment of Biology, Stanford University, Stanford, United States; 'Muscle Metabolism Discovery and Performance Unit, GlaxoSmithKline, Research Triangle Park, Durham, United States

Competing interests: The authors declare that no competing interests exist.

Funding: See page 15

Received: 21 June 2013

Accepted: 09 November 2013

Published: 24 December 2013

Reviewing editor: Christopher Glass, University of California, San Diego, United States

(c) Copyright Mowers et al. This article is distributed under the terms of the Creative Commons Attribution License, which permits unrestricted use and redistribution provided that the original author and source are credited.
Abstract Obesity produces a chronic inflammatory state involving the NFKB pathway, resulting in persistent elevation of the noncanonical IKB kinases IKKE and TBK1. In this study, we report that these kinases attenuate $\beta$-adrenergic signaling in white adipose tissue. Treatment of 3T3-L1 adipocytes with specific inhibitors of these kinases restored $\beta$-adrenergic signaling and lipolysis attenuated by TNF $\alpha$ and Poly (I:C). Conversely, overexpression of the kinases reduced induction of Ucp1, lipolysis, cAMP levels, and phosphorylation of hormone sensitive lipase in response to isoproterenol or forskolin. Noncanonical IKKs reduce catecholamine sensitivity by phosphorylating and activating the major adipocyte phosphodiesterase PDE3B. In vivo inhibition of these kinases by treatment of obese mice with the drug amlexanox reversed obesity-induced catecholamine resistance, and restored PKA signaling in response to injection of a $\beta-3$ adrenergic agonist. These studies suggest that by reducing production of cAMP in adipocytes, IKKE and TBK1 may contribute to the repression of energy expenditure during obesity.

DOI: 10.7554/eLife.01119.001

\section{Introduction}

Obesity generates a state of chronic, low-grade inflammation in liver and adipose tissue accompanied by macrophage infiltration and the local secretion of inflammatory cytokines and chemokines that attenuate insulin action, resulting in insulin resistance and the subsequent development of Type 2 diabetes (Wellen and Hotamisligil, 2005; Hotamisligil, 2006; Lumeng et al., 2007; Shoelson et al., 2007). Numerous studies indicate a strong correlation between inflammation and insulin resistance across several populations (Hotamisligil, 2006). Moreover, genetic ablation or pharmacological inhibition of inflammatory pathways can dissociate obesity from insulin resistance (Hotamisligil, 2006; Shoelson et al., 2007), suggesting that local inflammation can be a key step in the generation of insulin resistance.

The transcription factor NFKB and its inflammatory program play an important role in the development of insulin resistance in obese liver and adipose tissue (Yuan et al., 2001; Arkan et al., 2005; Wunderlich et al., 2008; Chiang et al., 2009). NFKB is activated by the IKB kinase (IKK) family, which has four members: IKKa, IKKß, IKKE, and TBK1. IKKa and IKK $\beta$ act with the scaffolding partner NEMO to activate NFKB (Hacker and Karin, 2006). Although pharmacologic inhibition or genetic ablation of IKK $\beta$ defined a role for this kinase in insulin resistance (Yuan et al., 2001; Arkan et alo, 2005), the roles of the noncanonical kinases IKKE and TBK1 are less certain. 
eLife digest Obesity is a complex metabolic disorder that is caused by increased food intake and decreased expenditure of energy. Obesity also increases the risk of developing type 2 diabetes, heart disease, stroke, arthritis, and certain cancers. There is considerable evidence to suggest that adipose tissue becomes less sensitive to catecholamines such as adrenaline in states of obesity, and that this reduced sensitivity in turn reduces energy expenditure. However, the details of this process are not fully understood.

It is well established that obesity generates a state of chronic, low-grade inflammation in liver and adipose tissue, accompanied by the secretion of signaling proteins that prevent fat cells from responding to insulin, which leads to type 2 diabetes. Activation of the NFKB pathway is thought to have a central role in causing this inflammation. Now Mowers et al. have investigated whether inflammation caused by activation of the NFKB pathway also has a role in producing catecholamine resistance in fat cells.

Obesity-dependent activation of the NFKB pathway increases the levels of a pair of enzymes, IKK $\varepsilon$ and TBK1. Mowers et al. found that elevated levels of these two enzymes reduced the ability of certain receptors (called $\beta$-adrenergic receptors) in the fat cells of obese mice to respond to catecholamines. High levels of the two enzymes also resulted in lower levels of a second messenger molecule called cAMP, which increases energy expenditure by elevating fat burning. However, treating the fat cells with drugs that interfere with the two enzymes restored sensitivity to catecholamine, allowing the fat cells to burn energy.

Mowers et al. also treated obese mice with amlexanox, a drug that inhibits these enzymes, and found that this treatment made the mice sensitive to a synthetic catecholamine that triggered the release of energy from fat. Mowers et al. suggest, therefore, that IKKE and TBK1 respond to inflammation in the body by reducing catecholamine signaling, thus preventing energy expenditure. Drugs targeting these enzymes may be useful for treating conditions like obesity or type 2 diabetes.

DOI: 10.7554/eLife.01119.002

We recently reported that both mRNA and protein expression levels of IKKE and TBK1 are increased in adipose tissue from mice fed a high fat diet (Chiang et al., 2009). Both of these kinases are increased as a consequence of the inflammatory program in obesity (Reilly et al., 2013), and contain NFKB regulatory sites in their promoter regions, allowing them to be induced upon NFKB activation (Kravchenko et al., 2003). Deletion of the IKKE gene rendered mice partially resistant to some of the deleterious effects of high fat feeding, including weight gain, insulin resistance, hepatic steatosis, and systemic inflammation (Chiang et al., 2009). We report, in this study, that IKKE and TBK1 can desensitize lipolytic signaling in white adipose tissue in response to $\beta$-adrenergic agonists by phosphorylating and increasing the activity of PDE3B, in the process decreasing CAMP levels. Thus, induction of these noncanonical IKB kinases might contribute to catecholamine resistance during obesity, and blocking their activity has the potential to increase energy expenditure as an anti-obesity and anti-diabetes therapy.

\section{Results}

\section{IKK $\varepsilon$ and TBK1 overexpression decrease sensitivity to the $\beta$-adrenergic/ cAMP pathway in 3T3-L1 adipocytes}

Sympathetic activation of adipose tissue plays a key role in maintaining energy balance by stimulating lipolysis and fat oxidation (Coppack et al., 1994; Langin, 2006; Festuccia et al., 2011). Activation of $\beta$-adrenergic signaling by either $\beta$-adrenergic agonists or cold exposure in white and brown adipose tissue initiates a cascade of events through cyclic AMP (cAMP), culminating in the transcriptional upregulation of Ucp1, which results in increased proton leak and energy expenditure (Himms-Hagen et al., 2000; Cao et al., 2004; Yehuda-Shnaidman et al., 2010). Our previous studies revealed that compared to wild-type (WT) controls, IKKE-deficient mice exhibited increased energy expenditure while on a high fat diet (HFD), accompanied by increased expression of Ucp1 in white adipose depots (Chiang et al., 2009). Interestingly, increased energy expenditure in IKKE-deficient mice was only seen in HFD-fed mice (Chiang et al., 2009), suggesting that upon induction of IKKE during obesity, the 
kinase might repress an increased adaptive thermogenic response to overnutrition. To explore this possibility, we overexpressed IKKE in 3T3-L1 adipocytes and examined Ucp1 gene expression after treatment with the non-selective $\beta$-adrenergic agonist, isoproterenol (ISO), or the $\beta_{3}$-adrenergic agonist, CL-316,243. Fold difference in Ucp1 gene expression was calculated by normalization of relative Ucp1 mRNA levels in treated relative to control samples. Treatment of empty vector-expressing cells with ISO or CL-316,243 resulted in a 1.6-fold or twofold increase in Ucp1 mRNA levels, respectively (Figure 1A).

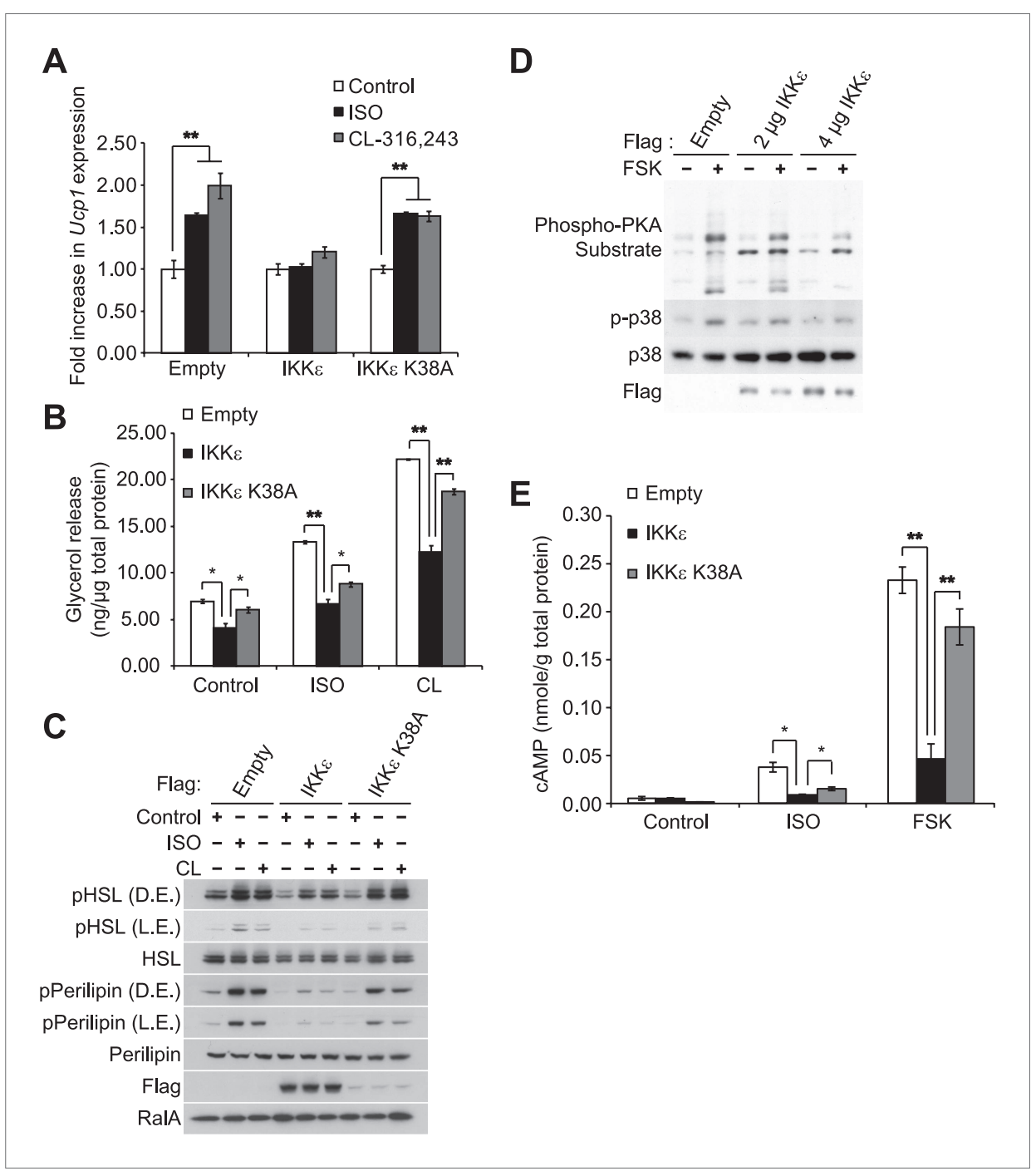

Figure 1. IKKE and TBK1 overexpression decrease sensitivity to the $\beta$-adrenergic/CAMP pathway in 3T3-L1 adipocytes.

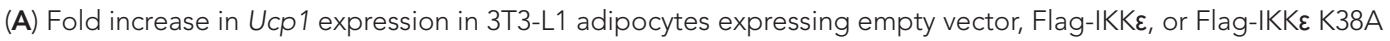
following treatment with or without $10 \mu \mathrm{M}$ ISO (black bars) or $10 \mu \mathrm{M} \mathrm{CL-316,243} \mathrm{(CL,} \mathrm{gray} \mathrm{bars)} \mathrm{for} 4 \mathrm{hr}$. ${ }^{* *} \mathrm{p}<0.01$. Performed in triplicate. (B) Glycerol release from 3T3-L1 adipocytes expressing empty vector (white bars), Flag-IKKE (black bars), or Flag-IKKE K38A (gray bars) treated with or without $10 \mu \mathrm{M}$ ISO or $10 \mu \mathrm{M} \mathrm{CL} .{ }^{*} \mathrm{p}<0.05$ and ${ }^{* *} \mathrm{p}<0.01$. Performed in triplicate. (C) Immunoblots of whole cell lysates from Figure 1B. Results were replicated in triplicate. D.E. stands for dark exposure and L.E. stands for light exposure. (D) Immunoblots of whole cell lysates from 3T3-L1 adipocytes expressing empty vector or Flag-IKKE treated with or without $50 \mu \mathrm{M}$ FSK for 15 min. Results were replicated

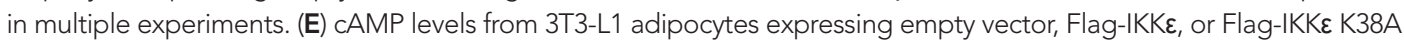
treated with or without $10 \mu \mathrm{M}$ ISO or $50 \mu \mathrm{M}$ FSK for $15 \mathrm{~min} .{ }^{* \star} \mathrm{p}<0.0001$ and ${ }^{*} \mathrm{p}<0.05$. Performed in triplicate. DOI: 10.7554/eLife.01119.003

The following figure supplements are available for figure 1:

Figure supplement 1. IKKE and TBK1 overexpression decrease sensitivity to the $\beta$-adrenergic/cAMP pathway in 3T3-L1 adipocytes.

DOI: 10.7554/eLife.01119.004 
The induction of Ucp1 gene expression in response to ISO or CL-316,243 was blunted when WT IKKE was overexpressed in these cells. However, expression of the kinase-inactive mutant of IKKE K38A (Fitzgerald et alo, 2003) was less effective, but still modestly repressed Ucp1 expression.

In addition to increased Ucp1 expression, IKKE knockout mice also exhibited increased lipolysis and fat oxidation (Chiang et al., 2009), suggesting that decreased lipolysis in adipose tissue from obese mice might result in part from increased expression of IKKE and TBK1 (Chiang et al., 2009). We thus modeled the obesity-dependent increase in the noncanonical IKKs by overexpressing IKKE in 3T3-L1 adipocytes, followed by assay of glycerol release in response to ISO or CL-316,243. Although both isoproterenol and CL-316,243 increased lipolysis in empty vector-expressing cells, overexpression of WT IKKE reduced the lipolytic effects of isoproterenol and CL-316,243 by greater than $40 \%$, and also reduced basal glycerol release (Figure 1B). The reduction in lipolysis by IKKE overexpression was accompanied by dramatically reduced phosphorylation of HSL and perilipin in response to ISO or CL-316,243 (Figure 1C). Expression of the catalytically inactive kinase was less effective in blocking lipolytic signaling, although the levels of protein achieved by overexpression were lower compared to the WT kinase (Figure 1B,C, Figure 1-figure supplement 1A). Overexpression of TBK1 reduced phosphorylation of HSL in response to isoproterenol or the adenylyl cyclase activator, forskolin (Figure 1-figure supplement 1B). Identical results were obtained when IKKE was overexpressed in 3T3-L1 adipocytes stimulated with forskolin (Figure 1D), as detected by western blotting with an anti-phospho-PKA substrate motif antibody. Overexpression of IKKE also repressed the phosphorylation of p38 (p-p38) in response to forskolin (Figure 1D) or isoproterenol (Figure 1-figure supplement 1A), whereas overexpression of IKKE K38A was without effect (Figure 1-figure supplement 1A). While glycerol release is likely the result of changes in HSL and perilipin phosphorylation, it is important to note that we have not directly assayed whether re-esterification of glycerol intermediates are also affected. Taken together, these data suggest that similar to what is observed in obesity, overexpression of IKKE or TBK1 can repress lipolytic signaling. The partial effectiveness of the kinase-inactive mutants is puzzling, but may reflect their activation of endogenous IKKE or TBK1 kinases due to dimerization (Larabi et al., 2013; Tu et al., 2013).

Since PKA signaling is responsible for Ucp1 induction in response to catecholamines (Klein et alı, 2000; Cao et al., 2001), we explored the possibility that both IKKE and TBK1 might reduce $\beta$-adrenergic sensitivity of adipocytes by decreasing cAMP levels. IKKE overexpression in 3T3-L1 adipocytes reduced by greater than $80 \%$ the increase in CAMP levels produced by both isoproterenol and forskolin, whereas overexpression of IKKE K38A did not (Figure 1E). Previous studies have shown that decreased sensitivity to adrenergic stimuli in adipose tissue can result from reduced $\beta$-adrenergic receptors (Reynisdottir et alo, 1994) or increased expression of $\alpha_{2}$-adrenergic receptors (Stich et al., 2002). These studies represent the first demonstration that defects distal to the adrenergic receptor may also contribute to catecholamine resistance, and suggest that IKK $\varepsilon$ and TBK1 can attenuate the $\beta$-adrenergic/ cAMP pathway in response to $\beta$-adrenergic stimuli in adipocytes in a cell-autonomous manner, and further that induction of these kinases during obesity may account for decreased energy expenditure by reducing sensitivity of adipocytes to $\beta$-adrenergic stimulation.

\section{Prolonged treatment with TNFa decreases the sensitivity of adipocytes to $\beta$-adrenergic stimulation in a manner dependent on the activity of IKK $\varepsilon$ and TBK1}

Obesity is accompanied by infiltration of proinflammatory macrophages into adipose tissue; these cells secrete inflammatory cytokines, such as TNFa, which generate insulin resistance by stimulating catabolic pathways (Hotamisligil, 2006; Lumeng et al., 2007; Ye and Keller, 2010; Ouchi et al., 2011). Although TNFa is known to increase lipolysis in adipocytes (Zhang et al., 2002; Souza et al., 2003; Green et al., 2004; Plomgaard et al., 2008), there is also evidence of a counterinflammatory response in obesity that may serve to repress energy expenditure (Gregor and Hotamisligil, 2011; Saltiel, 2012; Calay and Hotamisligil, 2013; Reilly et al., 2013). We thus used TNFa to model the inflammatory milieu of obese adipose tissue in cell culture to determine whether the cytokine might also regulate $\beta$-adrenergic signaling in this context. While short-term treatment with TNFa augmented the increase in cAMP produced by forskolin treatment, this effect declined after $12 \mathrm{hr}$. After $24 \mathrm{hr}$ of exposure, TNFa inhibited the production of the second messenger produced by forskolin (Figure 2figure supplement 1A). Thus, the catabolic effects of the proinflammatory cytokine TNFa in adipocytes are transient and followed by an inhibitory phase. 
Our previous studies revealed that treatment of 3T3-L1 adipocytes with TNFa for $24 \mathrm{hr}$ induced the expression of IKKE and increased TBK1 phosphorylation at the active site in a manner that was dependent on the activity of IKK $\beta$ and the NFKB pathway (Reilly et al., 2013). We thus wondered whether the repression of $\beta$-adrenergic sensitivity produced by longer-term treatment with TNFa might be due to increased activity of the noncanonical IKKs. Long-term treatment with TNFa repressed the induction of Ucp 1 gene expression in response to $\beta$-adrenergic stimuli (Figure 2-figure supplement 1B), whereas the expression of IKKE mRNA (Ikbke) was upregulated, as previously reported (Reilly et al., 2013). Treatment of 3T3-L1 adipocytes with TNFa for $24 \mathrm{hr}$ decreased glycerol release in response to both isoproterenol and forskolin in a dose-dependent manner (Figure 2A). TNFa treatment also decreased isoproterenol- and forskolin-stimulated cAMP production; an effect that was largely rescued by preincubation of cells with the selective, but structurally unrelated inhibitors of IKKE and TBK1, amlexanox (Figure 2B) (Reilly et al., 2013) or CAY10576 (Figure 2C) (Bamborough et al., 2006).

Isoproterenol-stimulated $\beta$-adrenergic signaling was also decreased by treatment of cells with TNFa (Figure 2D), as manifested by decreased phosphorylation of HSL, perilipin, and other proteins recognized by the PKA substrate motif antibody, whereas IKKE expression was concurrently upregulated and TBK1 phosphorylation was increased by the treatment with TNFa. Pretreatment of 3T3-L1 adipocytes with amlexanox also blocked the inhibitory effect of TNFa on isoproterenol-stimulated $\beta$-adrenergic signaling, as determined by western blotting with an anti-phospho-PKA substrate motif antibody, antiphospho-HSL, and anti-phospho-perilipin antibodies (Figure 2E). Interestingly, phosphorylation of p38 in response to isoproterenol was also dramatically augmented by amlexanox in a dose-dependent manner. Previous studies showed that the toll-like receptor 3 (TLR3) agonist, Poly (I:C), results in the direct activation of IKKE and TBK1 (Hemmi et al., 2004; Clark et al., 2009; Clark et al., 2011). Similar to TNFa, treatment of 3T3-L1 adipocytes with Poly (I:C) simultaneously reduced stimulation of cAMP production, lipolysis and phosphorylation in response to $\beta$-adrenergic stimulation (Figure 2-figure supplement $1 C-E)$, and the inhibitory effects of Poly $(I: C)$ on the sensitivity to isoproterenol stimulation were partially restored by amlexanox pretreatment, but not to the extent that was observed with TNFa treatment (Figure 2E). It is possible that Poly $(\mathrm{I}: \mathrm{C}$ )-induced desensitization of $\beta$-adrenergic pathway engages other pathways that are not directly regulated by $I K K \varepsilon$ and TBK1. These results suggest that obesity-associated inflammation leads to the activation of IKKE and TBK1, which produces reduced sensitivity of adipocytes to $\beta$-adrenergic stimulation.

\section{IKKE and TBK1 reduce CAMP levels through activation of PDE3B}

cAMP levels can also be regulated by phosphodiesterases, which cleave the second messenger and in the process dampen cAMP-dependent signals. Phosphodiesterase 3B (PDE3B) is the major PDE isoform expressed in adipocytes (Zmuda-Trzebiatowska et al., 2006). Genetic ablation or pharmacological inhibition of PDE3B in cells and in vivo revealed an important role for the enzyme in lipid and glucose metabolism (Choi et al., 2006; Berger et al., 2009; Degerman et al., 2011). Phosphorylation and activation of PDE3B by insulin in adipocytes is thought to be mediated by Akt, and cAMP itself acts as a negative feedback regulator of its own levels by promoting PKA-dependent phosphorylation and activation of PDE3B (Degerman et al., 2011).

Since we observed that cAMP production was impaired in forskolin or isoproterenol-stimulated 3T3-L1 adipocytes overexpressing IKKE (Figure 1E), we examined whether noncanonical IKKs might desensitize adrenergic stimulation through increased activity of PDE3B in adipocytes. Pretreatment with a nonspecific phosphodiesterase inhibitor, IBMX, in 3T3-L1 adipocytes expressing IKKE or TBK1 rescued the full stimulation of cAMP production in response to forskolin (Figure 3A). Interestingly, the selective PDE3B and PDE4 inhibitor, Zardaverine (Schudt et al., 1991), also blocked the inhibitory effects of IKKE and TBK1 overexpression on CAMP levels in response to isoproterenol and forskolin in 3T3-L1 adipocytes (Figure 3B), suggesting an important role for PDE3B as a target of the noncanonical IKKs.

We next examined whether IKKE and TBK1 directly phosphorylate PDE3B to regulate cAMP levels. Recombinant TBK1, Akt and PKA were incubated in vitro with [ $\left.\gamma-{ }^{32} \mathrm{P}\right] \mathrm{ATP}$ and purified PDE3B as a substrate. Phosphorylation was assessed by SDS-PAGE followed by autoradiography. TBK1 directly catalyzed the phosphorylation of PDE3B; phosphorylation was also produced by incubation with Akt and PKA, as previously reported (Kitamura et al., 1999; Palmer et al., 2007) (Figure 3C). IKKE also catalyzed this phosphorylation in vitro (data not shown). This increase in phosphorylation produced by in vitro incubation with TBK1, IKKE and PKA was also detected when PDE3B was blotted with antibodies 


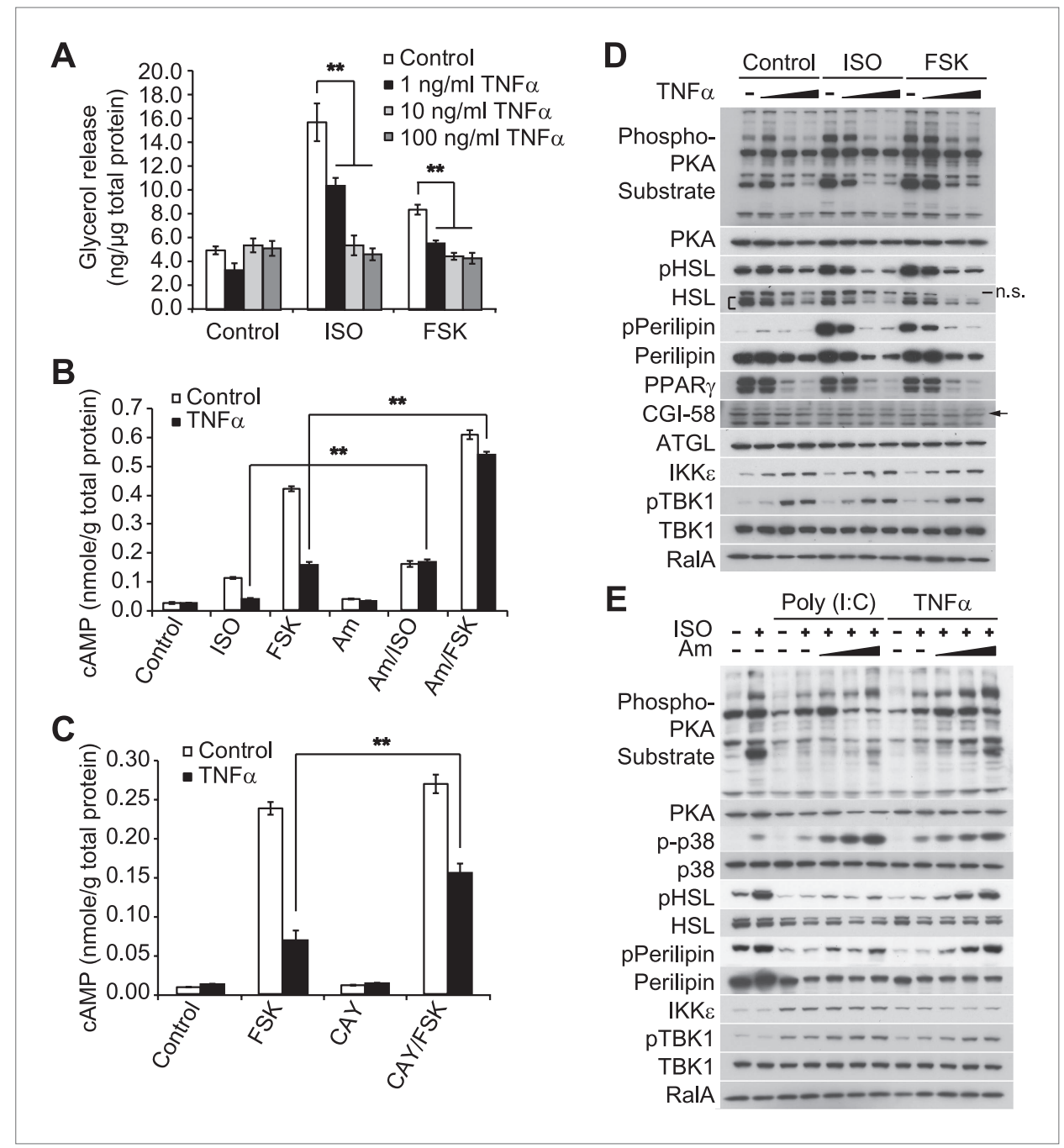

Figure 2. Prolonged treatment with TNFa decreases the sensitivity of adipocytes to $\beta$-adrenergic stimulation in a manner dependent on the activity of IKKE and TBK1. (A) Glycerol release from 3T3-L1 adipocytes treated with or without different concentrations of TNFa as indicated for $24 \mathrm{hr}$ followed by treatment with or without $10 \mu \mathrm{M}$ ISO or $50 \mu \mathrm{M}$ FSK. ${ }^{* *} \mathrm{p}<0.0001$. Performed in quadruplicate. (B) CAMP levels from 3T3-L1 adipocytes treated with or without $100 \mathrm{ng} / \mathrm{ml}$ TNFa for $24 \mathrm{hr}$ followed by treatment with or without $10 \mu \mathrm{M}$ ISO or $50 \mu \mathrm{M}$ FSK in the presence or absence of pretreatment of $50 \mu \mathrm{M}$ Amlexanox (Am). ${ }^{*} \mathrm{p}<0.0001$. Performed in quadruplicate. (C) cAMP levels from 3T3-L1 adipocytes treated with or without $100 \mathrm{ng} / \mathrm{ml}$ TNFa for $24 \mathrm{hr}$ followed by treatment with or without $50 \mu \mathrm{M}$ FSK in the presence or absence of pretreatment of $1 \mu \mathrm{M}$ CAY10576 (CAY). ${ }^{\star \star} p<0.0001$. Performed in triplicate. (D) Immunoblots of whole cell lysates from 3T3-L1 adipocytes treated with or without different concentrations of TNFa as same as Figure 2A for $24 \mathrm{hr}$ followed by treatment with or without $10 \mu \mathrm{M}$ ISO or $50 \mu \mathrm{M}$ FSK. Results were replicated in multiple experiments. '[' indicates total HSL. 'n.s.' represents non-specific band. Arrow indicates CGI-58. (E) Immunoblots of whole cell lysates from 3T3-L1 adipocytes treated with or without $50 \mathrm{ng} / \mathrm{ml}$ TNFa or $100 \mu \mathrm{g} / \mathrm{ml}$ poly (I:C) for $24 \mathrm{hr}$ followed by treatment with or without $10 \mu \mathrm{M}$ ISO for $15 \mathrm{~min}$ in the presence or absence of pretreatment with increasing concentrations $(0,10,50$, and $200 \mu \mathrm{M})$ of amlexanox for $30 \mathrm{~min}$. Results were replicated in multiple experiments. DOI: 10.7554/eLife.01119.005

The following figure supplements are available for figure 2:

Figure supplement 1. Prolonged exposure of inflammatory cytokines decreases the sensitivity of adipocytes to $\beta$-adrenergic stimulation. DOI: 10.7554/eLife.01119.006

that recognize the 14-3-3 binding motif (Figure 3-figure supplement 1A). When purified PDE3B was incubated with the same amount of recombinant TBK1 and canonical IKK $\beta$ kinases in vitro, phosphorylation of PDE3B by IKK $\beta$ was barely detectable, indicating a level of specificity in which PDE3B is 


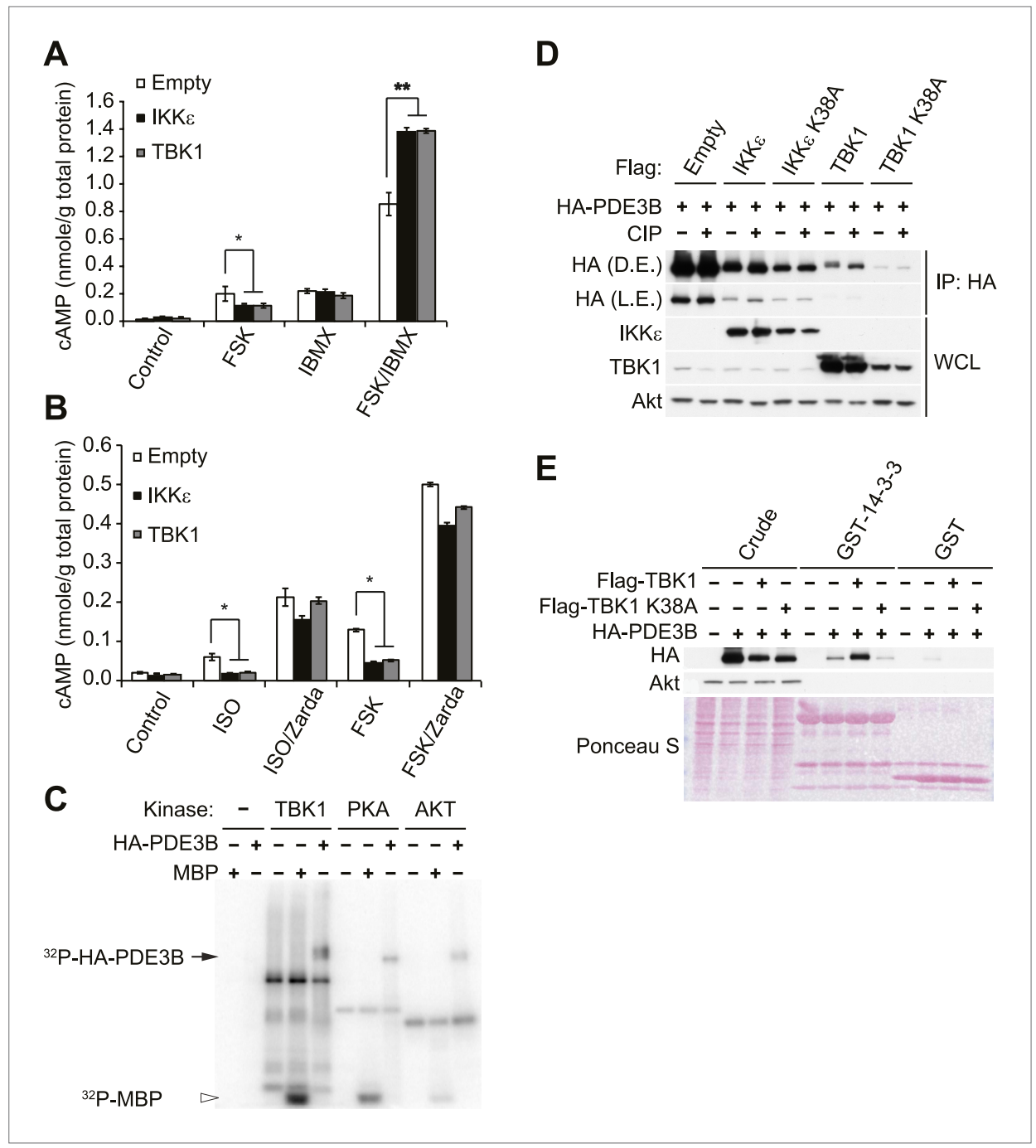

Figure 3. IKKE and TBK1 reduce CAMP levels through activation of PDE3B. (A) CAMP levels from 3T3-L1 adipocytes expressing empty vector, Flag-IKKE, or Flag-TBK1 treated with or without $50 \mu \mathrm{M} F S K, 250 \mu \mathrm{M}$ IBMX, or together for 15 min. ${ }^{*} p<0.05$ and ${ }^{* *} p<0.0001$. Performed in duplicate. (B) cAMP levels from 3T3-L1 adipocytes expressing empty vector, Flag-IKKE, or Flag-TBK1 treated with or without $10 \mu \mathrm{M}$ ISO or $50 \mu \mathrm{M}$ FSK together with or without $10 \mu \mathrm{M}$ Zardaverine (Zarda) for $15 \mathrm{~min} .{ }^{*} \mathrm{p}<0.05$. Performed in duplicate. (C) ${ }^{32} \mathrm{P}$ phospho-image of in vitro kinase reaction using either immunoprecipitated HA-PDE3B from HEK293T cells or $1 \mu \mathrm{g}$ MBP (myelin basic protein) as a substrate with recombinant kinases as indicated. Results were replicated in multiple experiments. (D) Immunoblots of immunoprecipitation with anti-HA antibodies followed by treatment with or without CIP (top panel) and whole cell

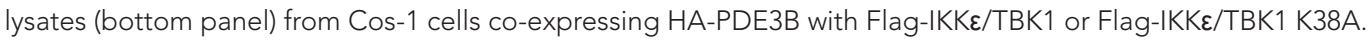
D.E. stands for dark exposure and L.E. stands for light exposure. Results were replicated in multiple experiments. (E) Immunoblots of GST-14-3-3 pulldown from HEK293T cells co-expressing HA-PDE3B with Flag-TBK1 or FlagTBK1 K38A. Ponceau S staining shows the amount of beads used in GST-14-3-3 pulldown. Results were replicated in multiple experiments.

DOI: 10.7554/eLife.01119.007

The following figure supplements are available for figure 3:

Figure supplement 1. IKKE and TBK1 interact with PDE3B in a manner dependent on the activity of IKKE and TBK1. DOI: 10.7554/eLife.01119.008

a better target of the noncanonical IKKs (Figure 3-figure supplement 1B). This phosphorylation was dose-dependent with respect to ATP (Figure 3-figure supplement 1C).

To determine whether IKKE can phosphorylate PDE3B in cells, we co-expressed IKKE and its inactive mutant K38A with HA-tagged PDE3B in HEK293T cells, followed by immunoprecipitation (IP) with anti-HA antibodies. Expression of IKKE in cells caused a shift in electrophoretic mobility of PDE3B, and 
this shift was not detected when IKKE K38A was expressed (Figure 3-figure supplement 1D). Phosphorylation of PDE3B was also detected after expression of IKKE but not its kinase-inactive mutant K38A in cells, as detected by blotting with antibodies that recognize the 14-3-3 binding motif. To determine whether this molecular shift was dependent on phosphorylation of PDE3B, HA-PDE3B was co-expressed in Cos-1 cells along with IKKE, TBK1 or their kinase inactive mutants, and HA immunoprecipitates were treated with or without calf intestinal phosphatase (CIP). Expression of both of the wild-type kinases reduced the electrophoretic mobility of PDE3B, which could be reversed by treatment with the phosphatase (Figure 3D, compare lane 3, 7 to lane 4, 8). Neither of the kinase-inactive mutants had an effect (Figure 3D, compare lane 5, 9 to lane 6, 10).

Previous studies suggested that IKKE and TBK1 bind to their respective substrates through a sequence that includes a ubiquitin-like domain (ULD) proximal to their kinase domain. This domain is highly conserved among the IKK family members, and is $49 \%$ identical between IKK $\varepsilon$ and TBK1 (Ikeda et al., 2007; May et al., 2004). To confirm that PDE3B is a bona fide substrate of IKKE and TBK1, we prepared a GST-ULD domain fusion protein from TBK1 and incubated this fusion protein with 3T3-L1 adipocyte lysates. The fusion protein specifically precipitated endogenous PDE3B from these lysates (Figure 3-figure supplement 1E). To explore further the interaction of these two proteins, we co-expressed WT TBK1 and its K38A mutant with HA-tagged PDE3B in HEK293T cells, and immunoprecipitated the protein with anti-HA antibodies. Kinase-inactive TBK1 was preferentially co-immunoprecipitated with PDE3B, whereas the interaction of PDE3B with WT TBK1 was barely detectable (Figure 3-figure supplement 1F). These data suggest that TBK1 and IKKE associate with substrates such as PDE3B, and subsequently dissociate upon phosphorylation.

Next, to test further the role of PDE3B phosphorylation by IKKE and TBK1 in initiating its interaction with 14-3-3 $\beta$, we prepared a GST-14-3-3 $\beta$ fusion protein which was incubated with lysates from HEK293T cells co-expressing TBK1 with PDE3B. PDE3B was preferentially pulled down by GST-14-3$3 \beta$ after phosphorylation by TBK1 but not by its inactive K38A mutant, whereas GST beads alone enriched neither PDE3B nor its phosphorylated form (Figure 3E).

\section{IKK $\varepsilon$ and TBK1 phosphorylate PDE3B at serine 318, resulting in the binding of 14-3-3 $\beta$}

To evaluate the regulatory role of PDE3B phosphorylation by IKKE and TBK1, we determined which sites are phosphorylated. HA-PDE3B was co-expressed in Cos-1 cells with IKKE and TBK1, and phosphorylated PDE3B was enriched by IP with anti-HA antibodies. Phosphorylation sites on human PDE3B were then determined by LC-MS/MS mass spectrometry. This analysis revealed that serines 22, 299, $318,381,463,467$, and 503 were phosphorylated by both kinases; there were no differences between the kinases (Figure 4A). Interestingly, the phosphorylation profile of PDE3B matched neither known Akt or PKA profiles (Lindh et al., 2007). However, phosphorylation on serine 299 and serine 318 had previously been identified on mouse PDE3B (residues equivalent to Serine 277 and 296 in mouse PDE3B) in adipocytes and hepatocytes in response to both insulin and forskolin (Lindh et al., 2007).

While several serine residues are known to be phosphorylated on PDE3B in response to stimuli, serine 318 (human) is the best characterized. This residue resides in a consensus phosphorylation sequence for both Akt and PKA, and also serves as a consensus 14-3-3 binding motif once phosphorylated (Lindh et al., 2007; Palmer et al., 2007). We thus created a Ser318Ala (S318A) mutant of PDE3B, and examined its interaction with a GST-14-3-3 $\beta$ fusion protein or by GST-14-3-3 overlay assay. Interestingly, despite incubation with TBK1, the phospho-defective, S318A mutant of PDE3B, did not specifically interact with GST-14-3-3 $\beta$, whereas the wild-type protein did (Figure 4B,C). In a GST pull-down assay, the molecular shift of PDE3B S318A was still detected by western blot (Figure 4B), indicating that phosphorylation of PDE3B by TBK1 on other sites still occurred, but were not crucial for 14-3-3 $\beta$ binding.

To examine the functional importance of the phosphorylation of PDE3B at Serine 318, we overexpressed WT PDE3B and its S318A mutant in 3T3-L1 adipocytes, and tested the response of the cells to TNFa. Overexpression of WT PDE3B in cells reduced the attenuation of forskolin-stimulated cAMP production and phosphorylation of HSL produced by TNFa, whereas PDE3B S318A was ineffective (Figure 4D, Figure 4-figure supplement 1A,B). These data suggest that although IKK $\varepsilon$ and TBK1 can phosphorylate $\mathrm{PDE} 3 \mathrm{~B}$ on several sites, serine 318 may be particularly important in the regulation of phosphodiesterase function by promoting the interaction between PDE3B and 14-3-3 3 . More importantly, this residue is the major site mediating the negative effects of IKKE and TBK1 on sensitivity of adipocytes to $\beta$-adrenergic stimulation. 


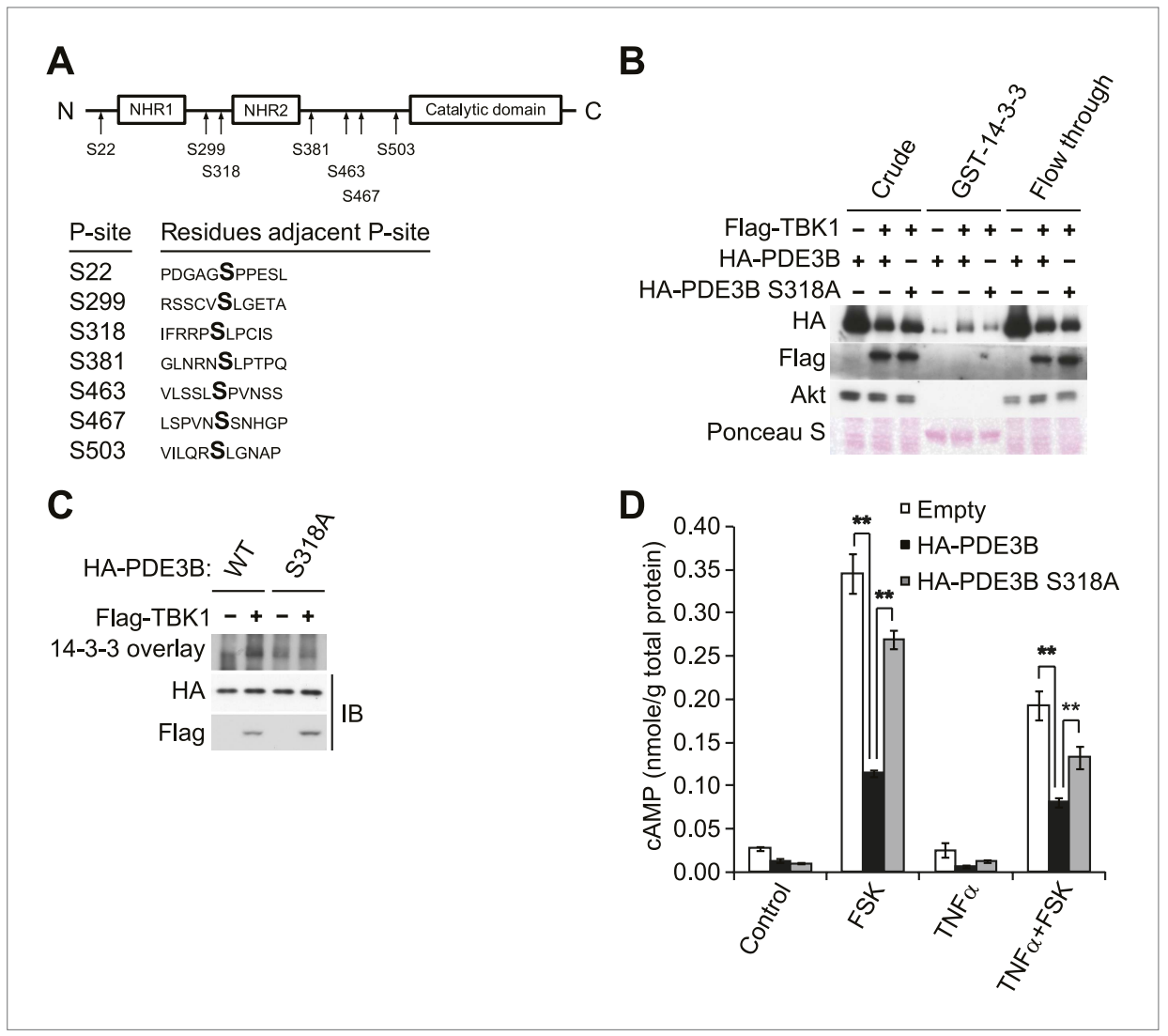

Figure 4. IKKE and TBK1 phosphorylate PDE3B at serine 318, resulting in the binding of 14-3-3B. (A) Summary of sites on PDE3B phosphorylated by IKKE or TBK1 (P-sites) from mass spectrometry experiments. (B) Immunoblots of GST-14-3-3 pulldown from HEK293T cells co-expressing HA-PDE3B or HA-PDE3B S318A with Flag-TBK1. Ponceau S staining shows the amount of beads used in GST-14-3-3 pulldown. Results were replicated in multiple experiments. (C) GST-14-3-3 overlay on nitrocellulose membrane (top blot) and an immunoblot (IB) of whole cell lysates from HEK293T cells co-expressing HA-PDE3B or HA-PDE3B S318A with Flag-TBK1 (bottom blot). Results were replicated in multiple experiments. (D) CAMP levels from 3T3-L1 adipocytes expressing empty vector, HA-PDE3B, or HA-PDE3B S318A treated with or without $100 \mathrm{ng} / \mathrm{ml}$ TNFa for $16 \mathrm{hr}$ followed by treatment with or without $25 \mu \mathrm{M}$ FSK for $15 \mathrm{~min}$. ${ }^{* *} \mathrm{p}<0.0001$ and ${ }^{* *} \mathrm{p}<0.01$. Performed in duplicate.

DOI: 10.7554/eLife.01119.009

The following figure supplements are available for figure 4:

Figure supplement 1. Overexpression of PDE3B in 3T3-L1 adipocytes reduces the attenuation of forskolin-stimulated $\beta$-adrenergic signaling produced by TNFa.

DOI: 10.7554/eLife.01119.010

\section{The IKK $\varepsilon / T B K 1$ inhibitor Amlexanox sensitizes $\beta$-adrenergic agonist- stimulated lipolysis in white adipose tissue in diet-induced obese mice}

Disruption of sympathetic activation of lipolysis and fat oxidation may play an important role in the development and maintenance of increased fat storage in obesity. Indeed, while numerous studies have demonstrated catecholamine resistance in obese adipose tissue (Jensen et al., 1989; Reynisdottir et al., 1994; Bougneres et al., 1997; Arner, 1999; Jocken and Blaak, 2008), the underlying mechanisms remain unclear. To test the functional importance of the noncanonical IKKs in maintaining energy balance in vivo, we investigated whether the administration of a selective inhibitor of IKK $\varepsilon$ and TBK1, amlexanox, can reverse diet-induced catecholamine resistance in rodents. We fed mice a high fat or normal diet, treated them with amlexanox by oral gavage for 4 days (prior to the point when weight loss is seen), and then gave a single intraperitoneal (IP) injection of the $\beta_{3}$-adrenergic agonist CL-316,243. Injection of CL-316,243 stimulated a threefold increase in serum FFA and glycerol levels in both vehicle and amlexanox-treated mice on normal diet (ND). The effect of CL-316,243 to increase serum FFAs was significantly attenuated in HFD-fed, vehicle-treated mice. However, HFD-fed mice treated with 
amlexanox responded like normal diet mice, despite the fact that they were weight matched with control HFD-fed mice (Figure 5A). The fold increase in serum glycerol levels was also significantly higher in amlexanox-treated HFD mice, as compared to vehicle-treated HFD-fed mice. In addition, ex vivo pretreatment of white adipose tissues from mice on a HFD with amlexanox enhanced glycerol release (Figure 5B). This effect was more pronounced in the inguinal fat depot, where amlexanox pretreatment increased phosphorylation of HSL, perilipin, and other proteins recognized by the PKA substrate motif antibody in response to CL-316,243 treatment compared to vehicle-pretreated tissues (Figure 5C). Amlexanox also concurrently increased the phosphorylation of TBK1 at Ser172 due to the relief of feedback inhibition, as previously reported with other inhibitors (Clark et alı, 2009; Reilly et al., 2013).

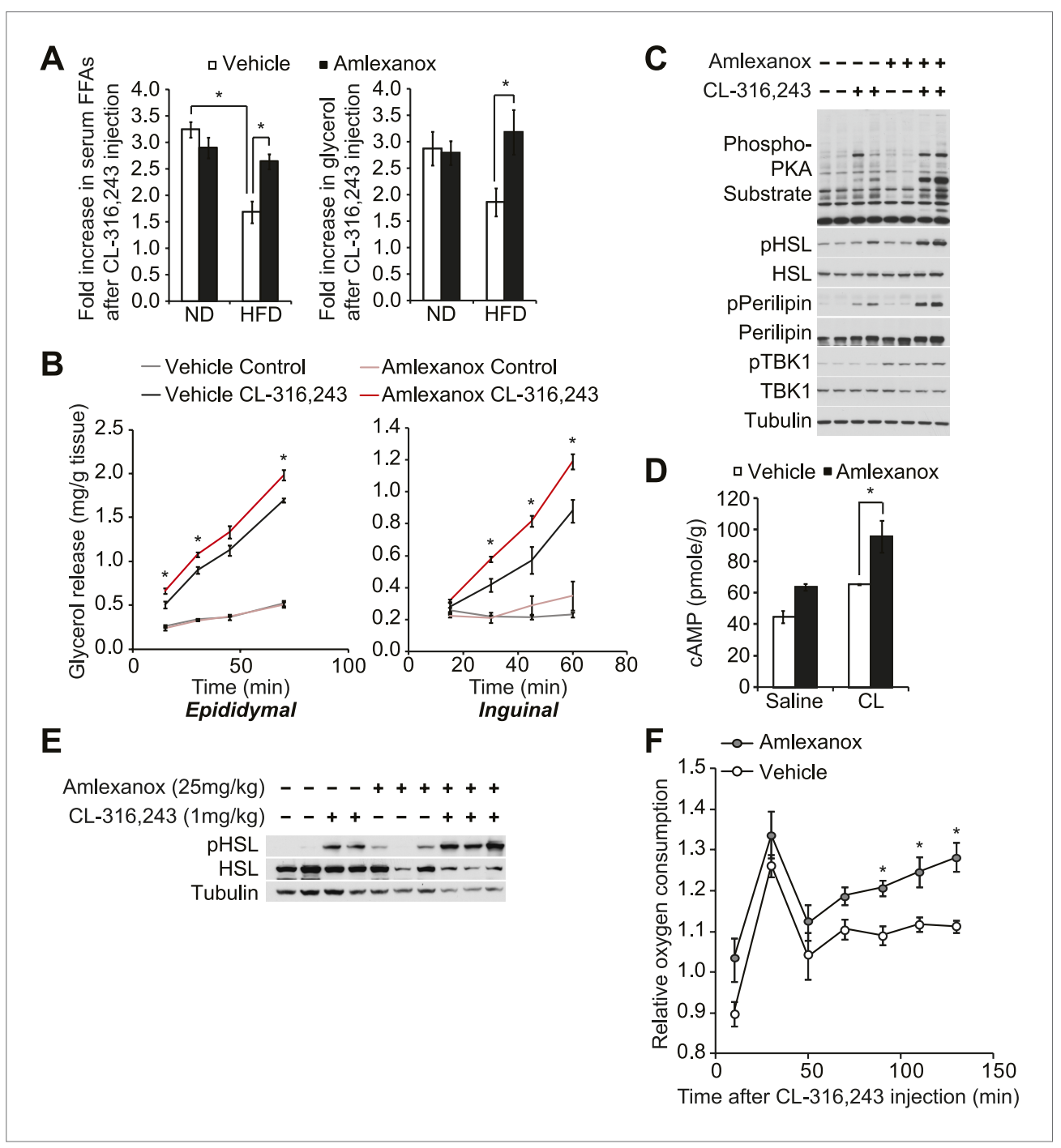

Figure 5. The IKKE/TBK1 inhibitor Amlexanox sensitizes $\beta$-adrenergic agonist-stimulated lipolysis in white adipose tissue in diet-induced obese mice. (A) Fold increase in serum FFA (left panel) and glycerol (right panel) levels 15 min after CL-316,243 injection in ND- or HFD-fed mice treated with amlexanox or vehicle control for 4 days. $n=7$ mice per group. ${ }^{*} p<0.05$. (B) Glycerol release from ex vivo epididymal (left panel) and inguinal (right panel) WATs after $1 \mathrm{hr}$ pretreatment with amlexanox or vehicle. CL-316,243 treatment was started at time zero. $n=6,3$ WAT pieces $\times 2$ mice. ${ }^{*} \mathrm{P}<0.05$. (C) Immunoblots in inguinal WAT lysates from Figure 5B after 60 min of CL-316,243 treatment. (D) CAMP levels in epididymal WAT 20 min after CL-316,243 (CL) or saline control injection in HFD-fed mice treated with amlexanox or vehicle control for 4 days. $n=2$ mice per saline-treated group and $n=3$ mice per CL-316,324-treated group. ${ }^{\star} p<0.05$. (E) Immunoblots in epididymal WAT 5 min after CL-316,243 or saline control injection in HFD-fed mice treated with amlexanox or vehicle control for 4 days. (F) Relative oxygen comsumption of mice in each treatment group. $n=7$ for the vehicle-treated group, $n=5$ for the amlexanox-treated group. ${ }^{*} P<0.05$ (Student's $t$ test). DOI: 10.7554/eLife.01119.011 
To examine whether inhibition of TBK1 and IKKE with amlexanox reverses resistance to catecholamineinduced lipolysis in vivo by increasing stimulation of cAMP production, we measured cAMP levels in epididymal adipose tissue from mice on HFD after CL-316,243 IP injection. Interestingly, levels of cAMP were increased after CL-316,243 IP injection in mice on HFD pretreated with amlexanox (Figure 5D). Consistent with this, HSL phosphorylation was also increased after CL-316,243 IP injection of HFD-fed mice pretreated with amlexanox (Figure 5E).

Our previous studies showed that increased expression of Ucp1 in white adipose depots resulted in increased energy expenditure in IKKE-deficient mice (Chiang et al., 2009) and amlexanox-treated mice (Reilly et al., 2013) while on a high fat diet but not on a normal diet. To examine whether inhibition of catecholamine resistance in obese adipose tissue by targeting noncanonical IKKs with amlexanox can lead to increase energy expenditure in diet-induced obese mice, we measured oxygen consumption rates of vehicle or amlexanox-treated HFD-fed mice after a single injection of CL-316,243 in metabolic cages. The effect of CL-316,243 to increase energy expenditure was more pronounced in amlexanoxtreated HFD-fed mice, as compared to vehicle-treated HFD-fed mice (Figure 5F). These data suggest that targeting the noncanonical IKKs with the selective inhibitor amlexanox ameliorated catecholamine resistance in obese adipose tissue.

\section{Discussion}

Decreased sympathetic activation of adipose tissue due to impaired catecholamine synthesis or sensitivity has been observed in obese patients (Reynisdottir et al., 1994; Stallknecht et al., 1997; Horowitz and Klein, 2000; Jocken et al., 2008). Obesity is commonly associated with blunted whole-body catecholamine-induced lipolysis (Horowitz and Klein, 2000). This is thought to occur through a number of mechanisms, including leptin resistance (Myers et al., 2010), as well as the reduced expression of $\beta$-adrenergic receptors (Reynisdottir et al., 1994) or increased expression of $\alpha_{2}$-adrenergic receptors (Stich et al., 2002). White adipose tissue and cultured isolated adipocytes from obese human and mouse models exhibit decreased cAMP-stimulated lipolysis and fat oxidation, due to reduced energy expenditure from decreased mitochondrial uncoupling (Yehuda-Shnaidman et al., 2010). This desensitization to adrenergic activation is also a feature of childhood onset obesity (Bougneres et al., 1997; Enoksson et al., 2000), and has been observed in adipocytes from first-degree relatives of obese subjects (Hellstrom et al., 1996).

We demonstrate here a novel link between obesity and reduced sympathetic activity and $\beta$-adrenergic sensitivity, through the inflammation-dependent induction of the noncanonical IKB kinases IKKE and TBK1. Obesity generates a state of low-grade inflammation in both humans and rodents, which involves activation of the NFKB pathway (Wellen and Hotamisligil, 2005; Hotamisligil, 2006; Shoelson et al., 2007). Upon its prolonged activation, NFKB induces the expression of the noncanonical IKB kinases IKKE and TBK1. The induction of these kinases was blocked by administration of anti-inflammatory agents to mice without producing weight loss, suggesting that they are expressed in response to inflammation rather than obesity per se (Reilly et al., 2013). Deletion of the IKKE gene rendered mice partially resistant to weight gain, insulin resistance, steatosis and the long-term inflammation produced by high fat diet (Chiang et al., 2009), and administration of the dual specificity IKKE/TBK1 inhibitor amlexanox to diet-induced obese or ob/ob mice produced even more profound effects (Reilly et al., 2013). The blockade of these kinases in obese rodents with amlexanox results in increased phosphorylation of PKA substrates in adipose tissue, along with increased expression of Ucp1, and improved rates of lipolysis and fat oxidation (Reilly et al., 2013). Amlexanox was shown to inhibit phosphodiesterase activity of rat peritoneal mast cells via an unknown mechanism (Makino et al., 1987). Together these data indicate that IKKE and TBK1 might exert their physiological effects in part by reducing the sensitivity of adipocytes to $\beta$-adrenergic stimulation via changes in cAMP.

Data presented here suggest that the molecular target of IKKE/TBK1 is the phosphodiesterase PDE3B. Upon increased expression in the obese state, these kinases can phosphorylate PDE3B, causing an increase in the activity of the enzyme that cleaves CAMP, reducing the stimulation of cAMP-dependent phosphorylation of proteins in response to sympathetic activation. These proteins include HSL and perilipin, responsible for $\beta$-adrenergic-stimulated lipolysis, and other proteins such as p38 that regulate expression of Ucp1. The reduced sensitivity to $\beta$-adrenergic activation can attenuate lipolysis and fatty acid oxidation, as well as adaptive thermogenesis.

Several issues deserve further attention. The first concerns the relative roles of the two noncanonical IKKs in this pathway. Both TBK1 and IKKE are induced in response to obesity-dependent inflammation, 
and appear to phosphorylate PDE3B on the same residues with equal efficiency. Although there are differences in expression of these kinases in other tissues (Shimada et al., 1999), and perhaps differences in the upstream signals that lead to their regulation (Wunderlich et al., 2008), their relative roles in controlling this pathway remain uncertain. Additionally, the mechanism by which PDE3B is regulated remains uncertain. While phosphorylation correlates well with decreased levels of cAMP in cells, we have been unable to demonstrate increased catalytic activity of the enzyme due to phosphorylation by IKKE, TBK1 or the other kinases (Kitamura et al., 1999; Palmer et al., 2007) thought to regulate the phosphodiesterase. Perhaps the phosphorylation-dependent binding of the enzyme to 14-3-3 exerts changes in its localization and access to its substrate, thus explaining increased activity in cells.

How is it that insulin resistance produced by inflammation fails to block continued energy storage? One possible explanation may lie in the homeostatic response to inflammation itself, typified by the induction of TBK1 and IKKE. Our data confirm previous findings that TNF $\alpha$ and perhaps other inflammatory cytokines can promote lipolytic processes in cells after short-term treatment, but that after longer exposure elicit an inhibitory response that appears to be the result of TBK1 and IKKE induction. Thus, these kinases may be part of a 'counter-inflammatory' program that attenuates the extent to which inflammatory signals are effective, and also serves to conserve energy by repressing lipolysis and fatty acid oxidation through activation of PDE3B. Interestingly, PDE3B is also a target of insulin action in adipocytes (Degerman et al., 2011). Thus, TBK1 and IKKE appear to co-opt insulin targets to conserve energy during obesity. These insights further suggest that the noncanonical IKKs might be interesting new therapeutic targets for the treatment of obesity and type 2 diabetes.

\section{Materials and methods}

\section{Reagents}

All chemicals were obtained from Sigma-Aldrich (Saint Louis, MO) unless stated otherwise. Anti-Flag antibody was obtained from Sigma, and anti-HA antibody was obtained from Santa Cruz Biotechnology (Santa Cruz, CA). Anti-IKKE, anti-TBK1, anti-phospho-TBK1 (Ser172), anti-AKT, anti-phospho-AKT (Ser473), anti-HSL, anti-phospho-HSL (Ser660), anti-p38, anti-phospho-p38, anti-perilipin, anti-ATGL and anti-PPARY antibodies were purchased from Cell Signaling Technology (Danvers, MA). Anti-phospho-perilipin (Ser522) was purchased from Vala Sciences Inc (San Diego, CA). Anti-CGI-58 was purchased from Novus Biologicals (Littleton, CO). Anti-RalA antibody was obtained from BD Bioscience (San Jose, CA). Anti-Ucp1 antibody was obtained from Alpha Diagnostics (San Antonio, TX). Anti-PDE3B was provided as a generous gift by the Dr Vince Manganiello (NHLBI, NIH). Enhanced chemiluminescence (ECL) reagents were purchased from Thermo Scientific (Rockford, IL). EDTA-free protease inhibitor tablet was purchased from Roche Diagnostics (Indianapolis, IN). Monoclonal anti-HA agarose (Sigma) was used for immunoprecipitations, performed using the manufacturer's protocol. The human PDE3B cDNA was kindly provided by Dr Morris Birnbaum (University of Pennsylvania). The human 14-3-3 $\beta$ cDNA was kindly provided by Dr Ken Inoki (University of Michigan) and subcloned into pKH3 (Chen et al., 2007) and pGEX-4T-1 vectors (GE Healthcare Life Sciences, MI). Amlexanox was purchased from Ontario Chemical Inc. (Guelph, Ontario, Canada). The TBK1/IKKE inhibitor CAY10576 was purchased from Cayman Chemical (Ann Arbor, MI).

\section{Cell culture and transfection}

3T3-L1 fibroblasts (American Type Culture Collection, Manassas, VA) were cultured and differentiated as described previously (Liu et al., 2005). The cells were routinely used within 7 days after completion of the differentiation process; only cultures in which $>90 \%$ of cells displayed adipocyte morphology were used. 3T3-L1 adipocytes were transfected on the second day post FBS using Amaxa Cell Line Nucleofector Kit L (Lonza, Houston, TX) according to the manufacturer's protocol. 3T3-L1 adipocytes were serum starved for $12 \mathrm{hr}$ with $0.5 \%$ fetal bovine serum (FBS) in Dulbecco's modified eagle medium (DMEM, Invitrogen, Grand Island, NY) prior to TNFa treatments (50 ng/ml unless otherwise noted). 3T3-L1 adipocytes were pre-treated for $1 \mathrm{hr}$ with amlexanox at the given concentrations. Alternatively, 3T3-L1 adipocytes were treated with $50 \mu \mathrm{M}$ forskolin or $10 \mu \mathrm{M}$ isoproterenol for $15 \mathrm{~min}$, after a $60 \mathrm{~min}$ amlexanox pretreatment. The cells were harvested for total RNA and analyzed by real-time PCR. Cell lysates were resolved on SDS-PAGE and analyzed by immunoblot using the indicated antibodies. HEK293T or Cos-1 cells were cultured to $90 \%$ confluence and transfected using Opti-MEM media 
(Invitrogen) and $3 \mu$ l Lipofectamine 2000 (Invitrogen) per $\mu g$ DNA according to manufacturer's protocol. Coexpression of IKKE or TBK1 with HA-PDE3B was done using a $2 \mu \mathrm{g}$ kinase: $1 \mu \mathrm{g}$ PDE3B ratio of the expression constructs.

\section{Western analyses}

Tissues were homogenized in lysis buffer (50 mM Tris, pH 7.5, 5 mM EDTA, 250 mM sucrose, 1\% NP40, $2 \mathrm{mM}$ DTT, $1 \mathrm{mM}$ sodium vanadate, $100 \mathrm{mM} \mathrm{NaF}, 10 \mathrm{mM} \mathrm{Na}_{4} \mathrm{P}_{2} \mathrm{O}_{7}$, and freshly added protease inhibitor tablet), then incubated for $1 \mathrm{hr}$ at $4^{\circ} \mathrm{C}$ (Chiang et al., 2009). Crude lysates were then centrifuged at $14,000 \times g$ for 15 min twice and the protein concentration was determined using BioRad Protein Assay Reagent (Bio-Rad, Hercules, CA). Samples were diluted in sodium dodecyl sulfate (SDS) sample buffer and boiled for $5 \mathrm{~min}$ at $95^{\circ} \mathrm{C}$. Proteins were resolved by SDS-polyacrylamide gel electrophoresis and transferred to nitrocellulose membranes (Bio-Rad, Hercules, CA). Individual proteins were detected with the specific antibodies and visualized on film using horseradish peroxidase-conjugated secondary antibodies (Bio-Rad, Hercules, CA) and Western Lightning Enhanced Chemiluminescence (Perkin Elmer Life Sciences, Waltham, MA).

\section{Animals and animal care}

Wild-type male C57BL/6 mice were fed a high fat diet consisting of $45 \%$ of calories from fat (D12451 Research Diets Inc., New Brunswick, NJ) starting at 8 weeks of age for up to 6 months, while normal diet C57BL/6 controls were maintained on normal chow diet consisting of $4.5 \%$ fat (5002 Lab Diet, St. Louis, MO). Animals were housed in a specific pathogen-free facility with a 12-hr light/12-hr dark cycle and given free access to food and water. All animal use was in compliance with the Institute of Laboratory Animal Research Guide for the Care and Use of Laboratory Animals and approved by the University Committee on Use and Care of Animals at the University of Michigan.

\section{Gene expression analysis}

Total RNA was extracted from differentiated 3T3-L1 adipocytes using the RNeasy Kit (Qiagen, Valencia, CA) with a DNase step. The Superscript First-Strand Synthesis System for RT-PCR (Invitrogen, Grand Island, NY) was used with random primers for reverse transcription. Real-time PCR amplification of the cDNA was performed on samples in triplicate with Power SYBR Green PCR Master Mix (Applied Biosystems, Carlsbad, CA) using the Applied Biosystems 7900HT Fast Real-time PCR System. Adrp was chosen as the internal control for normalization as its expression was not significantly affected by experimental conditions. Sequences of Ucp1 primers used in this study are 5'-AGGCTTCCAGTA CCATTAGGT-3' and 5'-CTGAGTGAGGCAAAGCTGATTT-3'. Sequences of Ikbke primers used in this study are 5'-ACAAGGCCCGAAACAAGAAAT-3' and 5'-ACTGCGAATAGCTTCACGATG-3'. Data were analyzed using the $2^{-\triangle A C T}$ method (Livak and Schmittgen, 2001).

\section{In vivo CL-316,243 treatment}

Mice were placed on a high fat diet for 6 months, then after 1 week of daily gavage with vehicle, mice were gavaged with either vehicle or amlexanox $(25 \mathrm{mg} / \mathrm{kg})$ daily for 4 days. On the fourth day, mice were injected with CL-316,243 (1 mg/kg) or saline control. For analysis of blood metabolites, serum samples were collected before and $15 \mathrm{~min}$ after the injection, via a submandibular bleed. Mice were euthanized and WAT samples were collected for CAMP measurement and western blot analysis, 15 min or 20 min after injection. Analysis of oxygen consumption was performed in metabolic cages, as previously described (Reilly et al., 2013), by the University of Michigan Metabolic Phenotyping Core. Relative oxygen consumption was obtained by normalization of oxygen consumption rates, after the CL-316,243 injection, to the oxygen consumption rates on day 3 in the same mouse after saline injection. Both injections were performed at $11 \mathrm{am}$.

\section{Ex vivo glycerol release lipolysis assay in white adipose tissue}

For experiments involving CL-316,243, pieces were pre-incubated for 30 min with amlexanox (100 $\mu M)$ or DMSO vehicle control; then the tissue pieces were transferred to fresh media with and without $10 \mathrm{mM} \mathrm{CL-316,243,} \mathrm{and} \mathrm{media} \mathrm{samples} \mathrm{were} \mathrm{collected} \mathrm{every} 15 \mathrm{~min}$ for $1 \mathrm{hr}$. To measure glycerol release, $10 \mu \mathrm{l}$ of supernatant was combined with $200 \mu \mathrm{l}$ of Free Glycerol Reagent from the Free Glycerol Determination Kit (Sigma) and allowed to incubate for $15 \mathrm{~min}$ at room temperature. Absorbance at $540 \mathrm{~nm}$ was measured to determine glycerol content and was normalized to determine glycerol production per mg of white adipose tissue. 


\section{Glycerol release lipolysis assay in 3T3-L1 adipocytes}

3T3-L1 adipocytes were incubated in DMEM (Invitrogen) without phenol red for $2 \mathrm{hr}$ at $37^{\circ} \mathrm{C}$. The cells then were incubated for $90 \mathrm{~min}$ at $37^{\circ} \mathrm{C}$ in HBSS-2\% fatty acid-free BSA with $10 \mu \mathrm{M}$ isoproterenol or $10 \mu \mathrm{M}$ CL-316,243. Free glycerol concentration was measured by reacting $25 \mu \mathrm{l}$ of conditioned media with $200 \mu$ l Free Glycerol Reagent (Sigma) and absorbance was measured at $540 \mathrm{~nm}$ using the manufacturer's protocol. Glycerol release was normalized to cellular protein content.

\section{cAMP enzyme immunoassay}

3T3-L1 adipocytes were treated with $\beta$-agonists and/or phosphodiesterase inhibitors and allowed to incubate for the indicated amount of time at $37^{\circ} \mathrm{C}$. The cells were lysed with $150 \mu \mathrm{l} 0.1 \mathrm{M} \mathrm{HCl}$, scraped and spun down. A cAMP Enzyme Immunoassay Kit (Sigma CA201) was used to quantify cAMP levels. $50 \mu \mathrm{l}$ of cell lysates was combined with $50 \mu \mathrm{l}$ Assay Buffer 2 in each well and cAMP levels were assayed according to the manufacturer's protocol. Tissue samples were homogenized in 5\% TCA, then extracted with water-saturated ether, and dried before resuspension in Assay Buffer 2.

\section{Glosensor CAMP assay in 3T3-L1 adipocytes}

$80 \mu$ l of packed 3T3-L1 cells was electroporated with $3 \mu \mathrm{g}$ of Glosensor 22-F using Amaxa Cell Line Nucleofector Kit L (Lonza) according to the manufacturer's protocol. Electroporated cells were resuspended in $10 \mathrm{ml}$ of L1-FBS media and $200 \mu \mathrm{l}$ per well was plated in six columns of an opaque, white, 96-well tissue culture plate (BD Bioscience, San Jose, CA). After $20 \mathrm{hr}$, media were changed to $100 \mu \mathrm{l}$ DMEM with $1.5 \mathrm{mg} / \mathrm{ml}$ luciferin and allowed to equilibrate for $1 \mathrm{hr}$. The cells were treated with $50 \mu \mathrm{M}$ forskolin and luminescence was read every $30 \mathrm{~s}$ for $75 \mathrm{~min}$.

\section{In vitro kinase assays}

In vitro kinase assays were performed by incubating purified kinase (IKKE, TBK1, IKK $\beta, P K A$, or AKT) in kinase buffer containing $25 \mathrm{mM}$ Tris ( $\mathrm{pH}$ 7.5), $10 \mathrm{mM} \mathrm{MgCl}, 1 \mathrm{mM}$ DTT, and $10 \mu \mathrm{M}$ ATP for $30 \mathrm{~min}$ at $30^{\circ} \mathrm{C}$ in the presence of $0.5 \mu \mathrm{Ci} \mathrm{Y}-\left[{ }^{32} \mathrm{P}\right]$-ATP and $1 \mu \mathrm{g}$ myelin basic protein (MBP) per sample as a substrate. IKKE and TBK1 were fused to MBP (maltose binding protein) and these fusion proteins were purified from insect SF9 cells by baculovirus expression system by Dr Stuart J Decker (Life Sciences Institute, University of Michigan). IKKß, PKA, and AKT kinases were purchased from Millipore (Billerica, MA). The kinase reaction was stopped by adding $4 \mathrm{X}$ sodium dodecyl sulfate (SDS) sample buffer and boiling for $5 \mathrm{~min}$ at $95^{\circ} \mathrm{C}$. Supernatants were resolved by SDS-polyacrylamide gel electrophoresis, transferred to nitrocellulose, and analyzed by autoradiography using a Typhoon 9410 phosphorimager (GE Life Sciences, Piscataway, NJ). The bands were quantified using ImageQuant.

\section{Calf-intestinal phosphatase dephosphorylation}

Calf intestinal phosphatase (CIP) was obtained from New England Biolabs (Ipswich, MA). Immunoprecipitated PDE3B was incubated for $1 \mathrm{hr}$ at $37^{\circ} \mathrm{C}$ in a $100 \mu$ reaction containing $50 \mathrm{mM}$ Tris $\mathrm{pH} 7.5,150 \mathrm{mM} \mathrm{NaCl}, 1 \% \mathrm{NP}-40$, EDTA-free protease, and $5 \mu \mathrm{ICI}$.

\section{Protein purification}

For assays requiring soluble protein, purified GST-14-3-3 $\beta$ protein was eluted from glutathione beads by washing beads with $10 \mathrm{mM}$ glutathione in PBS, $\mathrm{pH}$ 8.0. The elution was monitored by A280 readings, and fractions containing protein were pooled and dialyzed overnight against $4 \mathrm{~L}$ of ice-cold PBS. The proteins were then concentrated using an Amicon centrifugal filtration unit (Millipore). Concentrated proteins were stored at $-80^{\circ} \mathrm{C}$ in PBS containing $10 \%$ glycerol and $10 \mathrm{mM}$ DTT.

\section{GST-14-3-3 Pulldown}

For GST-14-3-3 pulldowns, cells were washed twice with ice-cold PBS and then lysed in $1 \mathrm{ml}$ of 14-3-3 pulldown buffer (PD buffer; $15 \mathrm{mM}$ Tris, pH 7.5, $150 \mathrm{mM} \mathrm{NaCl}, 0.5 \%$ NP-40, $1 \mathrm{mM}$ DTT) supplemented with a protease inhibitor tablet (Roche). Lysates were cleared by centrifuging at 13,000×g for 10 min and then were incubated with $\sim 10 \mathrm{mg}$ of GST or GST-14-3-3 $\beta$ bound to glutathione beads (GE Healthcare Life Sciences, MI) for $1.5 \mathrm{hr}$ at $4^{\circ} \mathrm{C}$. For samples treated with phosphatase, lysates were preincubated with $500 \mathrm{U}$ of calf intestinal phosphatase (New England Biolabs, Inc.) at $37^{\circ} \mathrm{C}$ for $1 \mathrm{hr}$ before adding GST-14-3-3 beads. The beads were washed three times with $1 \mathrm{ml}$ of PD buffer and then resuspended in $2 X$ SDS sample buffer. 


\section{Preparation of DIG-labeled proteins and overlay assay}

GST or GST-14-3-3 $\beta$ was labeled with DIG by incubating $25 \mathrm{mg}$ of protein with $2 \mathrm{ml}$ of $5 \mathrm{mM}$ Digoxigenin-3-O-methylcarbonyl- $\varepsilon$-aminocaproic acid-N-hydroxysuccinimide ester (DIG-NHS; Roche) in $350 \mathrm{ml}$ of PBS for $15 \mathrm{~min}$ at room temperature. The labeling reaction was stopped by adding $100 \mathrm{ml}$ of $1 \mathrm{M}$ Tris- $\mathrm{HCl}, \mathrm{pH}$ 7.4. Labeled protein was dialyzed against $1 \mathrm{~L}$ of $25 \mathrm{mM}$ Tris- $\mathrm{HCl}, \mathrm{pH} 7.4$ for $1 \mathrm{hr}$ at room temperature, then against $4 \mathrm{~L}$ of PBS, $\mathrm{pH} 7.4$ for $4 \mathrm{hrs}$ at $4^{\circ} \mathrm{C}$, and finally against $4 \mathrm{~L}$ of fresh PBS, $\mathrm{pH} 7.4$ for $16 \mathrm{hrs}$ at $4^{\circ} \mathrm{C}$. Labeled protein was then diluted in $25 \mathrm{ml}$ of TBS $(50 \mathrm{mM}$ Tris- $\mathrm{HCl}, \mathrm{pH} 7.4$, $150 \mathrm{mM} \mathrm{NaCl}$ ) containing $2 \mathrm{mg} / \mathrm{ml} \mathrm{BSA}$ (Sigma-Aldrich) and 0.01\% sodium azide (Sigma-Aldrich). DIG-labeled proteins were stored at $4^{\circ} \mathrm{C}$.

For overlay assays, PDE3B was immunoprecipitated from HEK293T cells and resolved by SDSPAGE. Proteins were transferred to a nitrocellulose membrane. The membrane was blocked at room temperature overnight in blocking buffer ( $5 \%$ skim milk in TBS-T). The membrane was then incubated with DIG-labeled proteins for at least $4 \mathrm{hr}$ at $4^{\circ} \mathrm{C}$ and then washed three times with TBS-T. The membrane was then incubated with blocking buffer containing anti-DIG HRP antibody (1:10,000; Roche) for $2 \mathrm{hr}$ at room temperature, and washed three times with TBS-T. Overlays were visualized by reacting with ECL western blotting substrate (Perkin Elmer Life Sciences, Waltham, MA).

\section{Mass spectrometry}

In-gel digestion followed by LC-MS/MS analysis was carried out by the mass spectrometry-based proteomics resource in the Department of Pathology, University of Michigan. Briefly, tryptic peptides were resolved on a nano-C18 reverse phase column and sprayed directly onto Orbitrap mass spectrometer (LTQ-Orbitrap XL, Thermofisher). Orbitrap was operated in a data-dependent mode to acquire one full MS spectrum (resolution of $30,000 @ 400 \mathrm{~m} / \mathrm{z}$ ) followed by MS/MS spectra on six most intense ions (top 6). Proteins were identified by searching data against human protein database (Uniprot, rel. 2010-9) using X!Tandem/TPP software suite. Oxidation of Met, carbamidomethylation of Cys and phosphorylation of Ser, Thr, and Tyr were considered as potential modifications (Maine et al., 2010).

\section{Statistical analyses}

Averaged values are presented as the mean \pm SEM. When comparing two groups, we performed Student's $t$ test to determine statistical significance. When more than two groups and two factors were investigated, we first performed a two-way analysis of variance (ANOVA) to establish that not all groups were equal. After a statistically significant ANOVA result, we performed between-group comparisons using the Tukey post hoc analysis for comparisons of all means and Sidak for comparisons of within factor main effect means. ANOVA and Tukey/Sidak tests were performed using GraphPad Prism version 6.

\section{Acknowledgements}

We thank J Hung, R Truscott, and B Poirier for excellent technical assistance, and X Peng for maintaining the mouse colony. We thank the members of the Saltiel laboratory for helpful discussions. We thank $\mathrm{V}$ Manganiello $(\mathrm{NHLBI}, \mathrm{NIH})$ for production and use of PDE3B antibodies and his expert input and M Birnbaum for the human PDE3B cDNA (University of Pennsylvania). We thank K Inoki (University of Michigan) for the human 14-3-3 $\beta$ cDNA. We also acknowledge technical support from the Michigan Diabetes Research and Training Center.

\section{Additional information}

Funding

\begin{tabular}{lll} 
Funder & Grant reference number & Author \\
\hline National Institutes of Health & F30DK089687 & Jonathan Mowers \\
\hline National Institutes of Health & RO1DK60591, R24DK090962 & Alan R Saltiel \\
\hline
\end{tabular}

The funder had no role in study design, data collection and interpretation, or the decision to submit the work for publication. 
Author contributions

JM, MU, Conception and design, Acquisition of data, Analysis and interpretation of data, Drafting or revising the article, Contributed unpublished essential data or reagents; SMR, Conception and design, Acquisition of data, Analysis and interpretation of data; JS, DL, Acquisition of data, Analysis and interpretation of data; S-HC, LC, Analysis and interpretation of data, Contributed unpublished essential data or reagents; ARS, Conception and design, Analysis and interpretation of data, Drafting or revising the article

Ethics

Animal experimentation: All animal use was in compliance with the Institute of Laboratory Animal Research Guide for the Care and Use of Laboratory Animals and approved by the University Committee on Use and Care of Animals at the University of Michigan. All of the animals were handled according to approved institutional animal care and use committee (IACUC) protocols (\#A3114-01) of the University of Michigan. The protocol was approved by the Committee on the Ethics of Animal Experiments of the University of Michigan (Permit Number: Pro00004673). The University of Michigan is fully accredited by the Association for Assessment and Accreditation of Laboratory Animal Care, International (AAALAC, Intl) and the animal care and use program conforms to the standards of "The Guide for the Care and Use of Laboratory Animals," Revised 1996.

\section{References}

Arkan MC, Hevener AL, Greten FR, Maeda S, Li ZW, Long JM, Wynshaw-Boris A, Poli G, Olefsky J, Karin M. 2005. IKK-beta links inflammation to obesity-induced insulin resistance. Natural Medicines 11:191-198. doi: 10.1038/ nm1185.

Arner P. 1999. Catecholamine-induced lipolysis in obesity. International Journal of Obesity and Related Metabolic Disorders 23(Suppl 1):10-13. doi: 10.1038/sj.ijo.0800789.

Bamborough P, Christopher JA, Cutler GJ, Dickson MC, Mellor GW, Morey JV, Patel CB, Shewchuk LM. 2006. 5-(1H-Benzimidazol-1-yl)-3-alkoxy-2-thiophenecarbonitriles as potent, selective, inhibitors of IKK-epsilon kinase. Bioorganic and Medicinal Chemistry Letters 16:6236-6240. doi: 10.1016/j.bmcl.2006.09.018.

Berger K, Lindh R, Wierup N, Zmuda-Trzebiatowska E, Lindqvist A, Manganiello VC, Degerman E. 2009. Phosphodiesterase 3B is localized in caveolae and smooth ER in mouse hepatocytes and is important in the regulation of glucose and lipid metabolism. PLOS ONE 4:e4671. doi: 10.1371/journal.pone.0004671.

Bougneres P, Stunff CL, Pecqueur C, Pinglier E, Adnot P, Ricquier D. 1997. In vivo resistance of lipolysis to epinephrine. A new feature of childhood onset obesity. The Journal of Clinical Investigation 99:2568-2573. doi: $10.1172 / \mathrm{JCl} 119444$.

Calay ES, Hotamisligil GS. 2013. Turning off the inflammatory, but not the metabolic, flames. Natural Medicines 19:265-267. doi: 10.1038/nm.3114.

Cao W, Daniel KW, Robidoux J, Puigserver P, Medvedev AV, Bai X, Floering LM, Spiegelman BM, Collins S. 2004. p38 mitogen-activated protein kinase is the central regulator of cyclic AMP-dependent transcription of the brown fat uncoupling protein 1 gene. Molecular and Cellular Biology 24:3057-3067. doi: 10.1128/MCB.24.7.3057. 3067.2004

Cao W, Medvedev AV, Daniel KW, Collins S. 2001. beta-Adrenergic activation of p38 MAP kinase in adipocytes: cAMP induction of the uncoupling protein 1 (UCP1) gene requires p38 MAP kinase. The Journal of Biological Chemistry 276:27077-27082. doi: 10.1074/jbc.M101049200.

Chen XW, Leto D, Chiang SH, Wang Q, Saltiel AR. 2007. Activation of RalA is required for insulin-stimulated Glut4 trafficking to the plasma membrane via the exocyst and the motor protein Myo1c. Developmental Cell 13:391-404. doi: 10.1016/j. devcel.2007.07.007.

Chiang SH, Bazuine M, Lumeng CN, Geletka LM, Mowers J, White NM, Ma JT, Zhou J, Qi N, Westcott D, Delproposto JB, Blackwell TS, Yull FE, Saltiel AR. 2009. The protein kinase IKKepsilon regulates energy balance in obese mice. Cell 138:961-975. doi: 10.1016/j.cell.2009.06.046.

Choi YH, Park S, Hockman S, Zmuda-Trzebiatowska E, Svennelid F, Haluzik M, Gavrilova O, Ahmad F, Pepin L, Napolitano M, Taira M, Sundler F, Stenson Holst L, Degerman E, Manganiello VC. 2006. Alterations in regulation of energy homeostasis in cyclic nucleotide phosphodiesterase 3B-null mice. The Journal of Clinical Investigation 116:3240-3251. doi: 10.1172/JCl24867.

Clark K, Peggie M, Plater L, Sorcek RJ, Young ER, Madwed JB, Hough J, Mclver EG, Cohen P. 2011. Novel cross-talk within the IKK family controls innate immunity. Biochemical Journal 434:93-104. doi: 10.1042/ BJ20101701.

Clark K, Plater L, Peggie M, Cohen P. 2009. Use of the pharmacological inhibitor BX795 to study the regulation and physiological roles of TBK1 and IkappaB kinase epsilon: a distinct upstream kinase mediates Ser-172 phosphorylation and activation. The Journal of Biological Chemistry 284:14136-14146. doi: 10.1074/jbc. M109.000414.

Coppack SW, Jensen MD, Miles JM. 1994. In vivo regulation of lipolysis in humans. Journal of Lipid Research 35:177-193. 
Degerman E, Ahmad F, Chung YW, Guirguis E, Omar B, Stenson L, Manganiello V. 2011. From PDE3B to the regulation of energy homeostasis. Current Opinion in Pharmacology 11:676-682. doi: 10.1016/j. coph.2011.09.015.

Enoksson S, Talbot M, Rife F, Tamborlane WV, Sherwin RS, Caprio S. 2000. Impaired in vivo stimulation of lipolysis in adipose tissue by selective beta2-adrenergic agonist in obese adolescent girls. Diabetes 49:2149-2153. doi: $10.2337 /$ diabetes.49.12.2149.

Festuccia WT, Blanchard PG, Deshaies Y. 2011. Control of brown adipose tissue glucose and lipid metabolism by PPARgamma. Frontiers in Endocrinology 2:84. doi: 10.3389/fendo.2011.00084.

Fitzgerald KA, McWhirter SM, Faia KL, Rowe DC, Latz E, Golenbock DT, Coyle AJ, Liao SM, Maniatis T. 2003. IKKepsilon and TBK1 are essential components of the IRF3 signaling pathway. Nature Immunology 4:491-496. doi: 10.1038/ni921.

Green A, Rumberger JM, Stuart CA, Ruhoff MS. 2004. Stimulation of lipolysis by tumor necrosis factor-alpha in 3T3-L1 adipocytes is glucose dependent: implications for long-term regulation of lipolysis. Diabetes 53:74-81. doi: 10.2337/diabetes.53.1.74.

Gregor MF, Hotamisligil GS. 2011. Inflammatory mechanisms in obesity. Annual Review of Immunology 29:415-445. doi: 10.1146/annurev-immunol-031210-101322.

Hacker H, Karin M. 2006. Regulation and function of IKK and IKK-related kinases. Science's STKE 2006:re13. doi: 10.1126/stke.3572006re13.

Hellstrom L, Langin D, Reynisdottir S, Dauzats M, Arner P. 1996. Adipocyte lipolysis in normal weight subjects with obesity among first-degree relatives. Diabetologia 39:921-928. doi: 10.1007/BF00403911.

Hemmi H, Takeuchi O, Sato S, Yamamoto M, Kaisho T, Sanjo H, Kawai T, Hoshino K, Takeda K, Akira S. 2004. The roles of two IkappaB kinase-related kinases in lipopolysaccharide and double stranded RNA signaling and viral infection. The Journal of Experimental Medicine 199:1641-1650. doi: 10.1084/jem.20040520.

Himms-Hagen J, Melnyk A, Zingaretti MC, Ceresi E, Barbatelli G, Cinti S. 2000. Multilocular fat cells in WAT of CL-316243-treated rats derive directly from white adipocytes. American Journal of Physiology Cell Physiology 279:C670-C681.

Horowitz JF, Klein S. 2000. Whole body and abdominal lipolytic sensitivity to epinephrine is suppressed in upper body obese women. American Journal of Physiology Endocrinology and Metabolism 278:E1144-E1152.

Hotamisligil GS. 2006. Inflammation and metabolic disorders. Nature 444:860-867. doi: 10.1038/nature05485.

Ikeda F, Hecker CM, Rozenknop A, Nordmeier RD, Rogov V, Hofmann K, Akira S, Dotsch V, Dikic I. 2007. Involvement of the ubiquitin-like domain of TBK1/IKK-i kinases in regulation of IFN-inducible genes. The EMBO Journal 26:3451-3462. doi: 10.1038/sj.emboj.7601773.

Jensen MD, Haymond MW, Rizza RA, Cryer PE, Miles JM. 1989. Influence of body fat distribution on free fatty acid metabolism in obesity. The Journal of Clinical Investigation 83:1168-1173. doi: 10.1172/JCI113997.

Jocken JW, Blaak EE. 2008. Catecholamine-induced lipolysis in adipose tissue and skeletal muscle in obesity. Physiology and Behavior 94:219-230. doi: 10.1016/j.physbeh.2008.01.002.

Jocken JW, Goossens GH, van Hees AM, Frayn KN, van Baak M, Stegen J, Pakbiers MT, Saris WH, Blaak EE. 2008. Effect of beta-adrenergic stimulation on whole-body and abdominal subcutaneous adipose tissue lipolysis in lean and obese men. Diabetologia 51:320-327. doi: 10.1007/s00125-007-0866-y.

Kitamura T, Kitamura Y, Kuroda S, Hino Y, Ando M, Kotani K, Konishi H, Matsuzaki H, Kikkawa U, Ogawa W, Kasuga M. 1999. Insulin-induced phosphorylation and activation of cyclic nucleotide phosphodiesterase 3B by the serine-threonine kinase Akt. Molecular and Cellular Biology 19:6286-6296.

Klein J, Fasshauer M, Benito M, Kahn CR. 2000. Insulin and the beta3-adrenoceptor differentially regulate uncoupling protein-1 expression. Molecular Endocrinology 14:764-773. doi: 10.1210/me.14.6.764.

Kravchenko VV, Mathison JC, Schwamborn K, Mercurio F, Ulevitch RJ. 2003. IKKi/IKKepsilon plays a key role in integrating signals induced by pro-inflammatory stimuli. The Journal of Biological Chemistry 278:26612-26619. doi: $10.1074 / j b c . M 303001200$.

Langin D. 2006. Adipose tissue lipolysis as a metabolic pathway to define pharmacological strategies against obesity and the metabolic syndrome. Pharmacological Research 53:482-491. doi: 10.1016/j.phrs.2006.03.009.

Larabi A, Devos JM, Ng SL, Nanao MH, Round A, Maniatis T, Panne D. 2013. Crystal structure and mechanism of activation of TANK-binding kinase 1. Cell Reports 3:734-746. doi: 10.1016/j.celrep.2013.01.034.

Lindh R, Ahmad F, Resjo S, James P, Yang JS, Fales HM, Manganiello V, Degerman E. 2007. Multisite phosphorylation of adipocyte and hepatocyte phosphodiesterase 3B. Biochimica et Biophysica Acta 1773:584-592. doi: 10.1016/j. bbamcr.2007.01.010.

Liu J, DeYoung SM, Zhang M, Cheng A, Saltiel AR. 2005. Changes in integrin expression during adipocyte differentiation. Cell Metabolism 2:165-177. doi: 10.1016/j.cmet.2005.08.006.

Livak KJ, Schmittgen TD. 2001. Analysis of relative gene expression data using real-time quantitative PCR and the 2(-Delta Delta C(T)) Method. Methods 25:402-408. doi: 10.1006/meth.2001.1262.

Lumeng CN, Deyoung SM, Saltiel AR. 2007. Macrophages block insulin action in adipocytes by altering expression of signaling and glucose transport proteins. American Journal of Physiology Endocrinology and Metabolism 292:E166-E174. doi: 10.1152/ajpendo.00284.2006.

Maine GN, Li H, Zaidi IW, Basrur V, Elenitoba-Johnson KS, Burstein E. 2010. A bimolecular affinity purification method under denaturing conditions for rapid isolation of a ubiquitinated protein for mass spectrometry analysis. Nature Protocols 5:1447-1459. doi: 10.1038/nprot.2010.109.

Makino H, Saijo T, Ashida Y, Kuriki H, Maki Y. 1987. Mechanism of action of an antiallergic agent, amlexanox (AA-673), in inhibiting histamine release from mast cells. Acceleration of cAMP generation and inhibition of phosphodiesterase. International Archives of Allergy and Applied Immunology 82:66-71. doi: 10.1159/000234292. 
May MJ, Larsen SE, Shim JH, Madge LA, Ghosh S. 2004. A novel ubiquitin-like domain in lkappaB kinase beta is required for functional activity of the kinase. The Journal of Biological Chemistry 279:45528-45539. doi: 10.1074/ jbc.M408579200.

Myers MG Jnr, Leibel RL, Seeley RJ, Schwartz MW. 2010. Obesity and leptin resistance: distinguishing cause from effect. Trends in Endocrinology and Metabolism 21:643-651. doi: 10.1016/j.tem.2010.08.002.

Ouchi N, Parker JL, Lugus JJ, Walsh K. 2011. Adipokines in inflammation and metabolic disease. Nature Reviews Immunology 11:85-97. doi: 10.1038/nri2921.

Palmer D, Jimmo SL, Raymond DR, Wilson LS, Carter RL, Maurice DH. 2007. Protein kinase A phosphorylation of human phosphodiesterase 3B promotes 14-3-3 protein binding and inhibits phosphatase-catalyzed inactivation. The Journal of Biological Chemistry 282:9411-9419. doi: 10.1074/jbc.M606936200.

Plomgaard P, Fischer CP, Ibfelt T, Pedersen BK, van Hall G. 2008. Tumor necrosis factor-alpha modulates human in vivo lipolysis. The Journal of Clinical Endocrinology and Metabolism 93:543-549. doi: 10.1210/jc.2007-1761.

Reilly SM, Chiang SH, Decker SJ, Chang L, Uhm M, Larsen MJ, Rubin JR, Mowers J, White NM, Hochberg I, Downes M, Yu RT, Liddle C, Evans RM, Oh D, Li P, Olefsky JM, Saltiel AR. 2013. An inhibitor of the protein kinases TBK1 and IKK-varepsilon improves obesity-related metabolic dysfunctions in mice. Natural Medicines 19:313-321. doi: 10.1038/nm.3082.

Reynisdottir S, Wahrenberg H, Carlstrom K, Rossner S, Arner P. 1994. Catecholamine resistance in fat cells of women with upper-body obesity due to decreased expression of beta 2-adrenoceptors. Diabetologia 37:428-435. doi: 10.1007/BF00408482.

Saltiel AR. 2012. Insulin resistance in the defense against obesity. Cell Metabolism 15:798-804. doi: 10.1016/j. cmet.2012.03.001.

Schudt C, Winder S, Muller B, Ukena D. 1991. Zardaverine as a selective inhibitor of phosphodiesterase isozymes. Biochemical Pharmacology 42:153-162. doi: 10.1016/0006-2952(91)90694-Z.

Shimada T, Kawai T, Takeda K, Matsumoto M, Inoue J, Tatsumi Y, Kanamaru A, Akira S. 1999. IKK-i, a novel lipopolysaccharide-inducible kinase that is related to IkappaB kinases. International Immunology 11:1357-1362. doi: 10.1093/intimm/11.8.1357.

Shoelson SE, Herrero L., Naaz A. 2007. Obesity, inflammation, and insulin resistance. Gastroenterology 132:2169-2180. doi: 10.1053/j.gastro.2007.03.059.

Souza SC, Palmer HJ, Kang YH, Yamamoto MT, Muliro KV, Paulson KE, Greenberg AS. 2003. TNF-alpha induction of lipolysis is mediated through activation of the extracellular signal related kinase pathway in 3T3-L1 adipocytes. Journal of Cellular Biochemistry 89:1077-1086. doi: 10.1002/jcb.10565.

Stallknecht B, Bulow J, Frandsen E, Galbo H. 1997. Desensitization of human adipose tissue to adrenaline stimulation studied by microdialysis. The Journal of Physiology 500:271-282.

Stich V, Marion-Latard F, Hejnova J, Viguerie N, Lefort C, Suljkovicova H, Langin D, Lafontan M, Berlan M. 2002. Hypocaloric diet reduces exercise-induced alpha 2-adrenergic antilipolytic effect and alpha 2-adrenergic receptor mRNA levels in adipose tissue of obese women. The Journal of Clinical Endocrinology and Metabolism 87:1274-1281. doi: 10.1210/jc.87.3.1274.

Tu D, Zhu Z, Zhou AY, Yun CH, Lee KE, Toms AV, Li Y, Dunn GP, Chan E, Thai T, Yang S, Ficarro SB, Marto JA Jeon H, Hahn WC, Barbie DA, Eck MJ. 2013. Structure and ubiquitination-dependent activation of TANKbinding kinase 1. Cell Reports 3:747-758. doi: 10.1016/j.celrep.2013.01.033.

Wellen KE, Hotamisligil GS. 2005. Inflammation, stress, and diabetes. The Journal of Clinical Investigation 115:1111-1119. doi: 10.1172/JCl25102.

Wunderlich FT, Luedde T, Singer S, Schmidt-Supprian M, Baumgartl J, Schirmacher P, Pasparakis M, Bruning JC. 2008. Hepatic NF-kappa B essential modulator deficiency prevents obesity-induced insulin resistance but synergizes with high-fat feeding in tumorigenesis. Proceedings of the National Academy of Sciences of the United States of America 105:1297-1302. doi: 10.1073/pnas.0707849104.

Ye J, Keller JN. 2010. Regulation of energy metabolism by inflammation: a feedback response in obesity and calorie restriction. Aging 2:361-368.

Yehuda-Shnaidman E, Buehrer B, Pi J, Kumar N, Collins S. 2010. Acute stimulation of white adipocyte respiration by PKA-induced lipolysis. Diabetes 59:2474-2483. doi: 10.2337/db10-0245.

Yuan M, Konstantopoulos N, Lee J, Hansen L, Li ZW, Karin M, Shoelson SE. 2001. Reversal of obesity- and diet-induced insulin resistance with salicylates or targeted disruption of Ikkbeta. Science 293:1673-1677. doi: 10.1126/science.1061620.

Zhang HH, Halbleib M, Ahmad F, Manganiello VC, Greenberg AS. 2002. Tumor necrosis factor-alpha stimulates lipolysis in differentiated human adipocytes through activation of extracellular signal-related kinase and elevation of intracellular cAMP. Diabetes 51:2929-2935. doi: 10.2337/diabetes.51.10.2929.

Zmuda-Trzebiatowska E, Oknianska A, Manganiello V, Degerman E. 2006. Role of PDE3B in insulin-induced glucose uptake, GLUT-4 translocation and lipogenesis in primary rat adipocytes. Cell Signal 18:382-390. doi: 10.1016/j.cellsig.2005.05.007. 